\title{
EFFECTIVE PLANNING AND SCHEDULING OF A RESIDENTIAL BUILDING WITH PROPER RISK ANALYSIS
}

\author{
Vinodh A S ${ }^{1}$, Shashikumar A ${ }^{2}$, G. Narayana ${ }^{3}$ \\ ${ }^{1}$ Post graduate Student, Department of Civil Engineering, S.J.C.I.T, Chickballapura, Karnataka, India \\ ${ }^{2}$ Assistant Professor, Department of Civil Engineering, S.J.C.I.T, Chickballapura, Karnataka, India \\ ${ }^{3}$ Professor \& Head of Department of Civil Engineering, S.J.C.I.T, Chickballapura, Karnataka, India
}

\begin{abstract}
As of now, the various functions of construction management such as planning, scheduling have been dealt in detail. Time duration of various activities has been fixed after studying various projects done before and also after discussing with senior engineers. Scheduling is done taken into consideration various aspects such as soil conditions, design aspects, management aspects, manpower, tools etc. The entire scheduling is done using MS-PROJECT 2010 and the detailed reports are presented using MS-OFFICE. This dissertation work is an attempt to show the importance of Planning, Scheduling and the best construction techniques and sequencing employed to enable the contractors and engineers to effectively and economically plan the sequence of various activities and properly allocate the manpower to complete the work as per schedule keeping Quality in control. Every project is unique in terms of its nature, complexity, scope and type. To make a project successful all the $10 \mathrm{knowledge}$ areas of PMBOK shall be performed. The need for study of risk management is important in India because it is less aware and its application in a project is unknown to many project managers. A good risk management avoids potential risks in the project and helps to achieve project objectives in a better way. Even though risk occur at regular interval and uncertain it can be managed; a prior risk management helps to start a project in a positive note and will keep the project team ready to face the upcoming risk and respond to them. The repetitive studies on risk management will spread awareness and keep us updated on new risk management checklist and questionnaire survey techniques.
\end{abstract}

Keywords: Project Management, Planning And Scheduling, Risk Management, Residential Project.

\section{INTRODUCTION}

CIVIL ENGINEERING WORK OF TODAY, gigantic though they may seem, will be dwarfed by the activities of the future. Enormous machines, improved methods and human ingenuity are already capable of contracting almost anything to the desires and design of man. Consequently, construction planning, scheduling, programming and control are becoming increasingly complex.

Construction is vital for any economy, development of a country and more so of a developing country. The construction industry accounts for $6-7 \%$ of the gross domestic products of many countries. The value of annual construction activities in the world exceeds one trillion dollars. Unfortunately due to the nature of construction business, knowledge gained in planning, scheduling, and controlling construction projects is rarely disseminated. Consequently, the cost of inefficiency is being occurred as a recurring cost. Moreover in various businesses, the rate of business failure of constructor is one of the highest. One of the reasons for the high rate of business is lack of knowledge.

All categories of organizations may face few internal and external factors that may make it uncertain whether and when they will achieve their objectives. This uncertainty is called Risk.

Most of the activities in organization undergo risk. To satisfy the risk criteria the organization has to find out the risk, know about the risk and finalize on the mitigate and control measures to be given to each risk. Many organizations may manage risk to some level, but risk management would be effective if the organization follows principles of risk management given in the standards. According to international standards, risk management can be applied in any area, at any time, as well as to any activity in the entire organization.

Project risk is an unknown obstacle while ongoing, which when occurs may or may not have impact on the project objectives i.e. cost, schedule, quality and scope. The impact of the project risk may be positive or negative. The negative impact will lead to threat and the positive impact will lead to opportunity.

Project risk management gives an idea to understand access and manage risk within the project. This output of the project risk management can be taken into account for many other project management processes. 


\section{PLANNING FOR CONSTRUCTION PROJECTS}

\subsection{Introduction}

Planning is the most important part of the management. Planning means future forecasting. This is a knowledge process requiring the use of intelligent faculties, imagine, forecast and prior decision, to decide in early as to what to be start, who can do and how it will do it to achieve the required goal, the old defects, present scope, and future analysis. Planning is important to ensure the proper utilization of man, money, and materials to achieve the objective of the project. Since the planning deals with future, it should be flexible so as to revise it time to time if the desired results are not achieved according to earlier planning.

\subsection{Steps in Project Planning}

Planning should be done most effectively for time and economic completion of a project. Following are the steps to be in effective planning.

- Finding the efficiencies of project. The first step in planning would be to find out the problem to be analyzed. This is necessary to formulate practical and realistic objectives.

- Identifying the activities involved, and assessing the approximate quantities of physical resource needed for each activity.

- Getting ready the logic community diagram to set up a relationship amongst activities, and integrating these diagrams to develop the project network or model

- Inspecting the task network to investigate the task period and deciding on relevant and non-critical movements.

- Exploring exchange- off between time and cost to reach on the optical time and rate for finishing the mission.

- Exploring work option with in special time and resource constrains and determining the venture work agenda.

- Opening specifications for planning and controlling for guys, fabric, apparatus rate and income for each and every work.

- Forecasting enter resources, production fee and nature of labor finished.

- Assigning bodily resources like guys, fabric, and gear exercise clever.

- Forecasting the project budget and price range allocation for reaching pursuits assign to every organizational unit.Design a control system for organization.

- Develop the resources, time and cost control method.

- Evolving an information communication system.

- Computerizing the planning and controlling system.

\subsection{Work Breakdown Structure}

Modern project management requires large network model to deal adequately with complexity in construction. The proven technique in the identification of large number of activities in a scientific and systematic manner is WBS. It is a logical product oriented subdivision of structure, units or even services. Project management requires effective information throughout all phases of project and between all personnel involved with the project plan. WBS establishes a hierarchy of element, which is to be planned for and executed.

Using this technique a large complex project is broken into smaller component until we get activities of the defined duration. A specific clearly defined link between elements of the defined duration. A specific clearly defined link between elements of the WBS is critical to the effectiveness of this approach.

One of the most important functions of WBS is to provide a disciplined frame work from which actual plan could be prepared.

A required meaningful report. The overall design of the structure of WBS is the key to an effective working system. Therefore it must be studied very carefully from an information point of view. Since WBS serves as a common information exchange language.It is the language, the code, and the device by which all information on the project is gathered. Therefore the structure should be built as a tree, such as the bottom level represent the detailed information and is large in scope. The base level of WBS structure is the lowest level of information required to manage the project. This is the lowest level of information that a user can foresee a need to communicate or monitor. Thus the structure is the key to an effective WBS.

\section{PROJECT SCHEDULING}

A construction challenge 'time table' may imply distinctive matters to the designers, contractors, sub-contractors, suppliers, and the house owners concerned in the building method. The schedule could imply the completion date required for section of the work. The time table could imply the agenda values the contactors post in opposition to which monthly growth repayments might be made. The time table might also consult with the system of sequencing and phasing character hobbies required to whole the mission. On this report development schedule manner a graphical presentation, which shows the phasing fee of building routine with the commencing and completion dates and sequential relationship among the many more than a few hobbies in a mission so that the work will also be applied in an orderly and powerful method.

\subsection{Preparation of Construction Schedule}

Project duration and completion dates are commonly determined by the owners need for the project. The date the owners need to occupy, use, or the rent the complete place is used to establish the completion of project date. The contractor, however, is traditionally responsible for the detailed planning and scheduling, necessary to know finishing of the project within the owner progress frame. 
The scheduler must understand how the varies materials, trade, equipment, and sub-contractors combined to produce a complete project. Many judgments must be made, and the schedule reliability depends largely on their quality.

Understanding how the varies materials, and sub-contractors combined to produce a complete project in an ability acquired only after years of study, observation, and experience. With the above said knowledge the constructional schedule is prepared in the following way.

- The assignment is split into quantity of operations

- The sequence of these operations will also be derived after realizing the connection correctly.

- The quantity of labor involved in every operation has to be calculated.

- The time required for completion of assignment good as for different routine are calculated. This can also be completed from the quantity of work involved and the price of performing each work.

Scheduling is main important role of planning process, which is an art. The quantity of the exercise is thus a function of the ability of the scheduler to combine creativity with experience in order to develop a product, which meets the needs of the project and thus client's objectives.

\subsection{Scheduling Techniques}

\subsubsection{BAR CHART}

In construction essentially the most usually used building agenda is BAR/GANTT chart. The BAR chart is widely used as building schedule due to the fact of its simplicity the benefit of practice, and comprehensible structure.

A BAR chart is a collection of movements listed in a vertical column with time represented on a horizontal scale. The begin and finish dates are shown for each undertaking and the length is indicated with the aid of the location of a horizontal bar to the right of description. Approximate date of begin and finish are proven for each exercise may also be determined from the horizontal tie scale at the top of the chart. The length of the bar represents the duration of the undertaking. Almost always the activity are listed in chronological order according to the and finish date but can be listed in every other manner depending on the planner.

The next steps are worried in getting ready the BAR chart:

1. Breakup the project into quantity of movements.

2. Record out the hobbies.

3. Find the interrelationship among these events.

4. Organize the movements in a systematic method.

5. Calculate the range if work and time required.

6. Draw the Bar chart in step with the scale.

The figure below shows Bar chart for the project, which has divisions A, B, C, D, E, F and G, which are to be performed for its timely and successful completion. The time required for the completion of these activities is $11,6,8,9$ and 16 units of time respectively.

\subsubsection{PERT}

It is a project management tool used for forecasting, controlling and analyzing a project. PERT was intended to assist in planning when no historical cost or time data was available with which to estimate overall project duration and cost. PERT is used in planning and controlling new product development and research projects where the uncertainty associated with cost and schedule must be evaluated.

PERT uses logic diagram to analyze the performance time. PERT charts are drawn as network diagram.

\subsubsection{CRITICAL PATH METHOD (CPM)}

The CPM or valuable path system was learned by means of DuPont and Remington Rand Univac in 1957. The study staff was once trying to check how high-quality to slash the time required to perform activities plant overhaul, preservation and building work. On the grounds that then, $\mathrm{CPM}$ is discovered to be of much use in the construction enterprise with functions within the development of enormous constitution like dams, bridges, tunnels, highupward push structures, and soforth.

CPM networks are customarily used for repetitive types of project, where particularly correct estimates of those initiatives are often area to quite small quantity of variant. For this reason CPM will not be suitable for research and development style of initiatives.

CPM is an recreation-oriented network. Hence, it is the activities that are planned and monitored. Activities are defined as operations, which require time to be carried out and which resource for completion. Events are milestones representing the beginning or completion of some activity or group of activities.

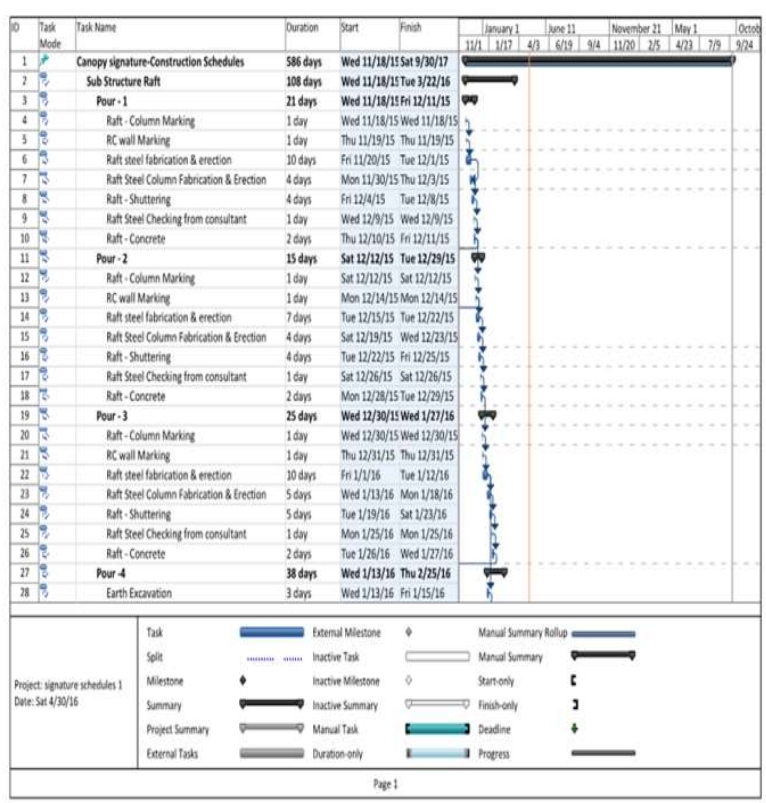

Fig 1 Sample picture of scheduling 


\section{RISK MANGEMENT}

Risk management is defines as "Systematic utility of administration insurance policies, systems and practices to the events of communicating, consulting, commencing the context, and deciding upon, analyzing, evaluating, treating, monitoring and reviewing risk."

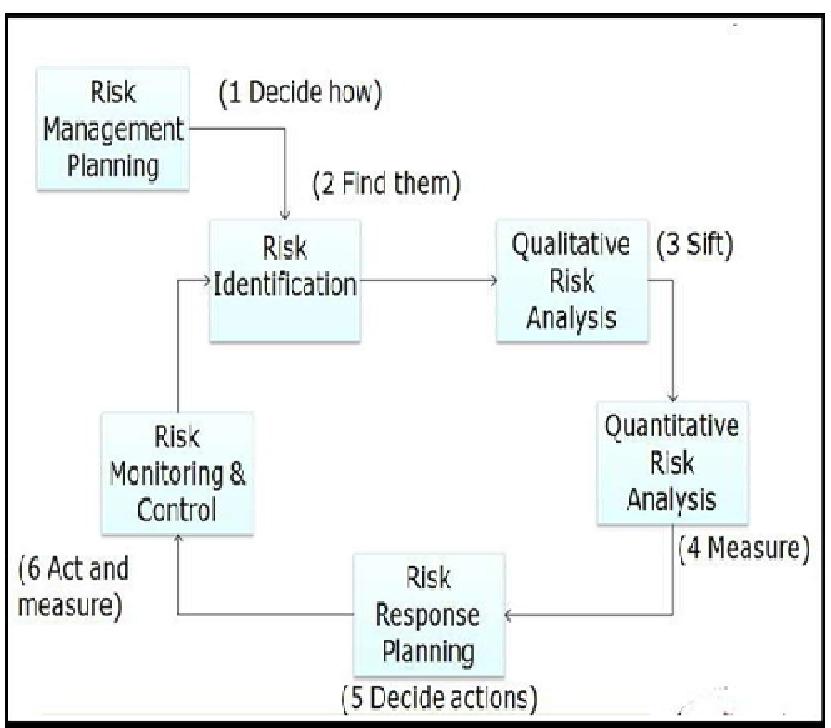

Fig 2 Risk analysis process

Risks do occur in every stage and activities involved in the project. There are many participants in the construction projects like contractors, consultants, owner or clients, suppliers etc.; they can equally be a source of risk.

The main objective of Risk identification is that, it gives an opportunity to identify potential risks. The potential risks identification helps in understanding these risks and gives scope for taking preventive measures on them. This will obviously reduce the impact of risk on project objectives.

Several tools and techniques are there for risk identification. But the project team should use the one that they are familiar with and effective. Risk identification helps in finding out potential risks, but these risks shall be managed in the further steps of risk management process.

Planning meetings and analysis are the techniques which help to prepare a risk management plan.May be considered as inputs to prepare risk management plan.

1) Documentation Review

2) Information Gathering Techniques

$>$ Brainstorm

$>$ Delphi analysis

$>$ Interview

$>$ Expert review

$>$ SWOT Analysis

$>$ Root Cause Analysis

$>$ Questionnaire Survey

3) Checklists

4) Diagramming Techniques.

\subsection{Questionnaire Survey}

A questionnaire can be prepared covering all the risk area or risk sources and judgments can be collected in the form of responses. Questionnaires can be a very general one with a non-specific prompts or questions and another can be a detailed, concentrative on only required subjects. This technique consumes lesser time than interview.

The questionnaire was designed by considering every processes of risk management i.e. from risk identification to risk response.

Following were the questions asked in the questionnaire:

1) Which of the risk factors were faced in the site?

2) If yes, please give description of the risk faced.

3) Scale on the probability of occurrence of risk i.e. low, moderate or high.

4) Scale on the impact of these risks on the project objective, i.e. cost, time and quality.

5) Describe on how the risks were responded.

All these questions were cautiously chosen and made sure that these answers do also help us in the proceeding analysis part. The questionnaire survey conducted in both the case studies on the project management team and the responses were further analyzed.

\subsection{Checklist Analysis}

Checklist cannot be developed if it is being the first project to carry out risk management in an organization. Checklist will be developed only with the help of previous projects documentation or experiences. This checklist helps in identification of potential risks.

\subsection{Qualitative Analysis}

The tools and techniques used for qualitative analysis are

Occurrence or say probability of occurrence and the impact are the two important terminologies here. its impact on project objectives is analyzed in this probability impact assessment.

The probability and impact are evaluated during the interview or meeting. An explanation to satisfy their answers will also be recovered. The tool used to analyze the risks will be the result.

Combines the probability of occurrence and impact scaling and gives a specific ratings to the risks.

\subsection{Quantitative Analysis}

After qualitative analysis the quantitative analysis should be performed. It emphasizes on finding of any risk there will be requirement of following three data.

- Time of a risk factor (i.e. for how much period this risk was affecting the project)

- Cost of risk factor

- The probability of occurrence of a risk factor. 
The tools and techniques used to represent quantitative analysis will be Torondo diagram as illustrated in Example to calculate impact of a risk factor in terms of cost -

Risk name: $\mathrm{x}$

Time of impact: $y$

Probability of occurrence: $\mathrm{z}$ (this data will be taken as average of probability scaling given by $n$ number of respondents in the project)

Cost of a risk: $\mathrm{C} 1$

Impact of risk on cost $=($ Probability $/ 10)($ cost of risk factor)

This cost calculation will be represented in Torondo diagram. And if there is negative impact of the risk it will be negative of the cost i.e. loss. If a risk is benefited and turns out to be positive impact then it will be taken as a profit.

The calculation of quantitative analysis as follows

\section{1) Weather Risk}

Time factor:

The time factor for weather risk can be taken as average of 3 to 4 months i.e. rainy season every year.

Therefore time factor $=3.5$ months

Probability scale:

The probability scale will be average of probability scale responses of 5 respondents i.e. $=(0.3+0.3+0.3+0.3+0) / 5=$ 0.24

\section{Cost factor:}

The cost for 36 months will be 615 crores and hence the cost for 3.5 months will be 59.79 crores.

Therefore, impact of Weather risk on cost $=($ probability $/ 10)$ cost $=(0.24 / 10) 59.79=1.43$ crores $/$ year

Impact of weather risk on cost $=1.43$ crores $/$ year.

\section{2) Delay Risk}

Time factor:

The time factor for delay risk can be taken as the project delay period only Therefore time factor $=6$ month.

Probability scale:

The probability scale will be average of probability scale responses of 5 respondents i.e. $=(0.3+0.3+0.3+0.3+0) / 5=$ 0.24

Cost factor:

The cost for 36 months will be 615 crores and hence the cost for 6 months it will be 102.5 crores.

Therefore, impact of Delay risk on cost $=($ probability $/ 10)$ cost

$=(0.24 / 10) 102.5=2.46$ crores

Impact of delay risk on cost $=2.46$ crores

\section{3) Labour Productivity Risk}

Time factor:

As we do not know the exact time factor, it will be assumed that the risk may affect the project for the duration of 6 months throughout the project

Therefore time factor $=6$ months

Probability scale:

The probability scale will be average of probability scale responses of 5respondents i.e. $=(0.3+0.3+0.3+0.3+0.3) / 5=$ 0.3

Cost factor:

The cost for 36 months will be 615 crores and hence the cost for 6 months it will be 102.5 crores.

Therefore, impact of Labour Productivity risk on cost $=$ (probability/10) cost $=(0.3 / 10) 102.5=3.07$ crores Impact of Labour productivity risk on cost $=3.07$ crores

\section{4) Procurement Risk}

Time factor:

As we do not know the exact time factor, it will be assumed that the risk may affect the project for the time peroid of 6 months throughout the project

Therefore time factor $=6$ months

Probability scale:

The probability scale will be average of probability scale responses of 5 respondents i.e. $=\{(0.3) 2+(0.5) 2+0\} / 5=$ 0.32

Cost factor:

The cost for 36 months will be 615 crores and hence the cost for 6 months it will be 102.5 crores.

Therefore impact of Procurement risk on cost $=$ (probability $/ 10)$ cost $=(0.32 / 10) 102.5=3.28$ crores Impact of Procurement risk on cost $=3.28$ crores

\section{5) Cost Overrun Risk}

Time factor:

As we do not know the exact time factor, it will be assumed that the risk may affect the project for the duration of 6 months throughout the project

Therefore time factor $=6$ months.

Probability scale:

The probability scale will be average of probability scale responses of 5 respondents i.e. $=0.28$ Cost factor:

The cost for 36 months will be 615 crores and hence the cost for 6 months it will be 102.5 crores.

Therefore impact of Cost overrun on cost $=($ probability/10) $\operatorname{cost}=(0.28 / 10) 102.5=2.87$ crores

Impact of Cost overrun risk on cost $=2.87$ crores 


\section{6) Equipment or Material Theft}

Time factor:

As we do not know the exact time factor, it will be assumed that the risk may affect the project for the time taken of 6 months throughout the project

Therefore time factor $=6$ months

\section{Probability scale:}

The probability scale will be average of probability scale responses of 5 respondents i.e. $=0.2$

\section{Cost factor:}

The cost for 36 months will be 615 crores and hence the cost for 6 months it will be 102.5 crores.

Therefore, impact of Equipment or material theft on cost $=$ (probability/10) $\operatorname{cost}=(0.2 / 10) 102.5=2.05$ crores

Impact of equipment or material theft on cost $=2.05$ crores

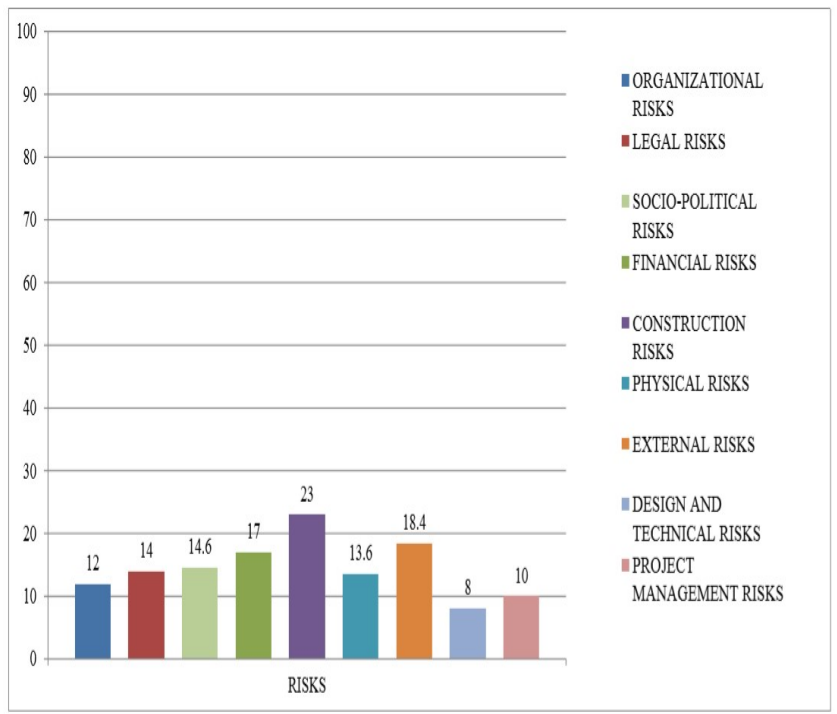

Fig 3. Results of questionnaire survey

\begin{tabular}{|c|c|}
\hline \multirow{2}{*}{ Objective } & Risk Factors \\
\hline \multirow{4}{*}{ Cost } & Delay \\
\cline { 2 - 2 } & Cost overrun \\
\cline { 2 - 2 } & Equipment and material theft \\
\hline \multirow{4}{*}{ Time } & Delay \\
\cline { 2 - 2 } & Labour productivity \\
\cline { 2 - 2 } & Procurements \\
\hline \multirow{4}{*}{ Quality } & Strikes \\
\cline { 2 - 2 } & Skills and commitment of labours \\
\cline { 2 - 2 } & Labour productivity \\
\hline & Procurements \\
\hline
\end{tabular}

Fig 4. Objectives of risk factor

\section{APPLICATION OF PROJECT RISK MANAGEMENT}

Step 1: Formation of Risk Management Team

Chance administration is principal and touchy system. So as to have a effective danger management software in any task a workforce can be fashioned which is able to exclusively work on hazard management best. The team individuals is also challenge participants or any external member who has skillability in threat administration. The team shall select one chief who is efficient and has just right expertise on chance management. As chance administration planning is the first step in risk management approach, the crew shall plan on proceed on managing and controlling the hazards. Planning of meetings and evaluation are the systems which help to arrange a danger management plan. Challenge scope declaration, fee administration plan and time table plan will function inputs for the plan.

Step 2: Risk Identification

Chance identification is the $2 \mathrm{~d}$ step in danger management method. In an effort to determine dangers there are several instruments and techniques as recounted in desk no 3.1.The crew shall choose any suitable technique to establish risks relying on the character of undertaking and working environment.A greater advocated chance identification process in any organization would be Brainstorming. If the project is to follow chance management procedure for the first time, then getting ready guidelines is the endorsed method. The risk management group shall review the records of earlier accomplished tasks of same institution and shall prepare a guidelines of risks confronted. Upon danger identification, subsequent step is to list the recognized dangers in organized way, which can be achieved by forming a hazard breakdown constitution.

Step 3: Preparation of Risk Register

A purpose of chance register is to report and control dangers easily. The threat administration workforce shall now put together a risk register and enter the identified dangers into it. No normal risk register is given in PMBOK and any organization can prepare their possess chance register in line with their requirement. The threat register shall be kept in website or place of business and the entire challenge individuals may have the possibility to enter the info in it. A traditional danger register can have small print of the following:

Step 4: chance evaluation

As noticeable in the case stories the easier served manner for qualitative analysis is chance and impact comparison making use of probability and have an impact on matrix. For that reason for qualitative analysis probability and influence assessment manner is encouraged. The chance management workforce shall decide upon proper likelihood of occurrence and impact scaling which serves as a window for assignment individuals to prefer and expense on probability and have an impact on. Extracting the info of probability and have an impact on scaling group can conclude on the character of danger i.e. Low, average or high chance. 
For quantitative analysis, sensitivity evaluation utilisingTorondo diagram is the advocated procedure. The staff shall calculate the have an effect on of each risk in my opinion.

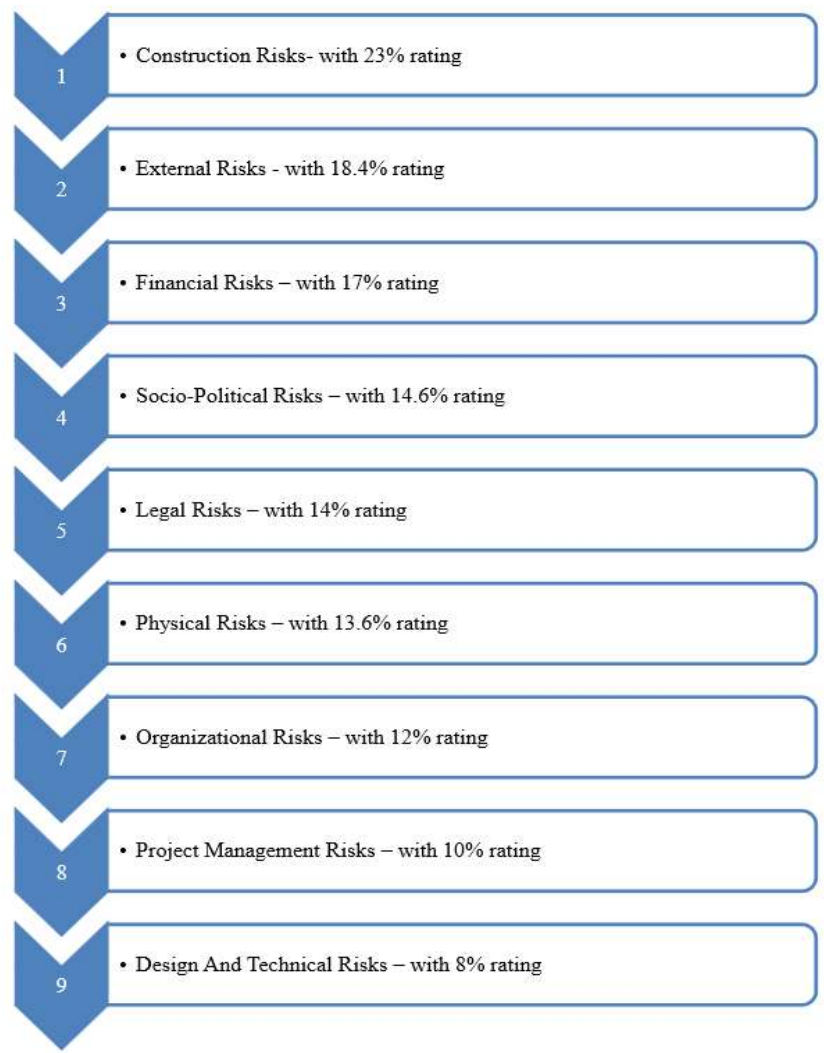

Fig 5. Rankings of risk categories

\section{CONCLUSION}

The main aim of the construction management is to minimize the complexity of planning and scheduling for work breakdown structure of project elements. Scheduling by usage of computer applications will gives best results for big construction projects, though the manpower and resource utilization will be good.

Risk management is the core factor in all construction management, as many people don't have the awareness about the risk factors. How efficiently the team members can handle the project risk factor by the experience.

We have taken the reference the old projects reports by using checklist and questionnaire survey for effective risk management. Recommandations has been proposed by rankings and risk factors, by following these one can minimize the risk factors and aanalysis.

\section{ACKNOWLEDGEMENTS}

I am thankful to Mr. Shashikumar A and Dr.GNarayana for their guidance. I also thank dept of civil engineering S.J.C institute of technology, chickallapura. And last but not the least my dear friends who have supported me to complete this projet work.

\section{REFERENCES}

[1]. Diego Echeverry, C. Williams Ibbs, Simon Kim (2011), " Sequencing Knowledge for construction Scheduling", Journal of construction engineering and management, Vol. 117, No.1, March.

[2]. Dora Cohenza-Zall, Alexander Laufer, Aviadshapira, Gregory A. Howell(1994),'Process of Planning during Construction', Journal of construction engineering and management, Vol.120, No. 3, September

[3]. Jonathan Irube, Alex Osiki (2009), ' An Investigation into the impact of Quality Management in the Construction Industry,' Au chi Polytechnic, Au chi, Nigeria.

[4]. LoredanaValentinaHedre (2013), 'Quality of construction Activity', Annals of the University of Petrosani, Economics, 10(3), 183-188

[5]. R. C. Walke and Prof. Dr. V. M. Topak (2012)."Risk Quantification Model For Construction Projects Using Score Model and EV Analysis Approach", International Journal Of Engineering Research And Application, (IJERA), Pp 2312-2317.

[6]. Mr. M. G. Bhandari and Dr. P. G. Gayakwad (2014). "Management Of Risk In Construction Projects in Maharashtra", International Journal Of Engineering Science Invention, IJESI, Vol. 3, Issue 1.

[7]. Patel AnkitMahendra, Jayeshkumar R. PitordaAnd J. J. Bhavsar (October 2013). "A Study of Risk Management Techniques for Construction Projects in Developing Countries", International Journal Of Innovative Technology And Exploring Engineering, IJITEE, Vol. 3, Issue 5.

\section{BIOGRAPHIES}

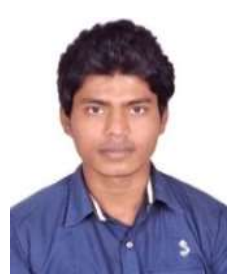

VINODH A S, Pursuing Final Year Mtech in Infrastructure Engineering and management in SJC institute of Technology, Chickballapur.

vinu.alline@gmail.com 9538973995

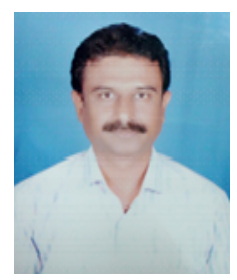

Mr.Shashi Kumar. A, Assistant Professor, Department of Civil Engineering, SJC institute of Technology, Chickballapur. He has wide experience in teaching field for over 15 years and currently pursuing his Ph.D.Ask0084@gmail.com

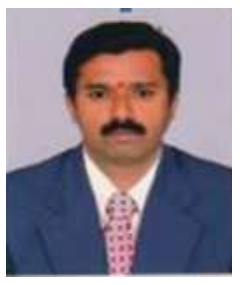

Dr.G.Narayana, Professor and Head of Civil Engineering Department, SJC institute of Technology, Chickballapur, have a wide experience in teaching and research in Structural Engineering field. $\mathrm{He}$ is also a Structural Designer and Consultant for many Projects.

narayanag@rediffmail.com 